\section{ANALYSIS OF ULTRASOUND IMAGE BIOLOGICAL IMAGE ALGORITHM IN THE RESTORATION OF MUSCLE GROUP MOVEMENT FUNCTION}

\author{
ANÁLISE DO ALGORITMO DE IMAGEM BIOLÓGICA POR ULTRASSOM NA RESTAURAÇÃO DA FUNÇÃODE \\ MOVIMENTO DO GRUPO MUSCULAR

\section{ANÁLISIS DEL ALGORITMO DE IMÁGENES BIOLÓGICAS DE IMÁGENES DE ULTRASONIDO EN LA RESTAURACIÓN DE LA FUNCIÓN DEMOVIMIENTO DEL GRUPOMUSCULAR}

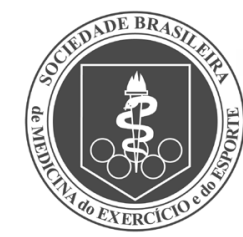

Original Article ARTIGO ORIGINAL Artículo Original

\begin{abstract}
Binghong Yan1 iD
(Physical Education Professional)

Cheng Wang' (D)

(Physical Education Professional)

1. Northwestern Polytechnical

University, Xi'an, China.

\section{Correspondence:}

Binghong Yan

Northwestern Polytechnical

University, Xi'an, China.

wangchenghn@yeah.net
\end{abstract}

\begin{abstract}
Objective: By studying the recognition effect of ultrasonic biological image data analysis on muscle group motion function, the evaluation value and significance of ultrasonic biomedical image combination algorithm on muscle group motion function are discussed. Methods: A Gabor filtering algorithm is proposed to smooth the original image. The MVEF algorithm is used to enhance the ultrasonic image and binary further the image again. Using the principle of the Hove transform, the thickness of the muscle is automatically estimated. Results: The square of correlation coefficients of the manual measurement method, Gabor filtering algorithm and MVEF algorithm are $91.3 \%, 91.3 \%$ and $87.8 \%$, respectively. The difference between the manual measurement and the estimation based on the Gabor filtering algorithm is $1.45 \pm 0.48 \mathrm{~mm}$. The difference between the results of manual measurement and the MVEF algorithm is $1.38 \pm 0.56 \mathrm{~mm}$. The computation time of the MVEF algorithm and Gabor algorithm are 5 seconds and 0.3 seconds, respectively. Conclusions: The algorithm proposed in this study can effectively measure the muscle thickness, fast, convenient and accurate, and can reflect the contractility of skeletal muscle well, which is of great value for the recognition and evaluation of muscle group movement function. Level of evidence Il; Therapeutic studies - investigation of treatment results.
\end{abstract}

Keywords: Ultrasonography; Algorithms; Motor activity.

\section{RESUMO}

Objetivo: Ao estudar o efeito de reconhecimento da análise de dados de imagem biológica ultrassônica na função de movimento do grupo muscular, o valor de avaliação e a importância do algoritmo de combinação de imagem biomédica ultrassônica na função de movimento do grupo muscular são discutidos. Métodos: Um algoritmo de filtragem Gabor é proposto para suavizar a imagem original. O algoritmo MVEFé usado para aprimorar ainda mais a imagem ultrassônica e binar a imagem novamente. Usando o princípio da transformada de H ove, a espessura do músculo é automaticamente estimada. Resultados: O quadrado dos coeficientes de correlação do método de medição manual, algoritmo de filtragem Gabor e algoritmo MVEF são 91,3\%, 91,3\% e 87,8\%, respectivamente. A diferença entre a medição manual e a estimativa baseada no algoritmo de filtragem Gabor é 1,45 $\pm 0,48 \mathrm{~mm}$. A diferença entre os resultados da medição manual e o algoritmo MVEF é de 1,38 $\pm 0,56 \mathrm{~mm}$. O tempo de cálculo do algoritmo MVEF e do algoritmo Gabor é de 5 segundos e 0,3 segundos, respectivamente. Conclusões: 0 algoritmo proposto neste estudo pode medir efetivamente a espessura muscular, de forma rápida, conveniente e precisa, e pode refletir bem a contratilidade do músculo esquelético, o que é de grande valor para o reconhecimento e avaliação da função de movimento do grupo muscular. Nível de evidência ll; Estudos terapêuticos- investigação dos resultados do tratamento.

Descritores: Ultrassonografia; Algoritmos; Atividade motora.

\section{RESUMEN}

Objetivo: Al estudiar el efecto de reconocimiento del análisis de datos de imágenes biológicas ultrasónicas sobre la función del movimiento del grupo muscular, se discuten el valor de evaluación y la importancia del algoritmo de combinación de imágenes biomédicas ultrasónicas sobre la función del movimiento del grupo muscular. Métodos: Se propone un algoritmo de filtrado de Gabor para suavizar la imagen original. El algoritmo MVEF se utiliza para mejorar aún más la imagen ultrasónica y volver a binar la imagen. Utilizando el principio de la transformada de Hove, el grosor del músculo se estima automáticamente. Resultados: El cuadrado de los coeficientes de correlación del método de medición manual, el algoritmo de filtrado de Gabor y el algoritmo MVEF son 91,3\%, 91,3\% y 87,8\%, respectivamente. La diferencia entre la medición manual y la estimación basada en el algoritmo de filtrado de Gabor es de 1,45 0,48 $\mathrm{mm}$. La diferencia entre los resultados de la medición manual y el algoritmo MVEF es 1,38 $\pm 0,56 \mathrm{~mm}$. El tiempo de cálculo del algoritmo MVEF y el algoritmo de 
Gabor son 5 segundos y 0,3 segundos respectivamente. Conclusiones: El algoritmo propuesto en este estudio puede medir eficazmente el grosor muscular, de forma rápida, conveniente y precisa, y puede reflejar bien la contractilidad del músculo esquelético, lo cual es de gran valor para el reconocimiento y evaluación de la función del movimiento de grupos musculares. Nivel de evidencia ll; Estudios terapéuticos-investigación de los resultados del tratamiento.

Descriptores: Ultrasonografía; Algoritmos; Actividad motora.

\section{INTRODUCTION}

The body's movement is done through the cooperation of the entire motor system. The driving force of sports is mainly the contraction of skeletal muscle. ${ }^{1-3}$ Skeletal muscle is the main power supply of human movement. In harm related to skeletal muscles, such as muscle pulleys, tendons tears, muscle atrophy, strokes such as stripes will bring a lot of inconvenience to people's daily lives, and even lead to the loss of movement. It can be seen that the skeletal muscle plays an important role in sports. ${ }^{4-5}$

With the rapid development of information technology, more and more attention is provided through mechanics, electricity, medical imaging, and other disciplines, providing accurate quantitative classification for rehabilitation evaluation methods. Through these quantitative research methods, the skeletal muscle movement model has been in-depth studies, which will help people understand the diseases such as muscle exercise dysfunction..$^{6-7}$ The composition of muscles is very complicated, which makes quantitative analysis methods to assess the function of skeletal muscle to become the difficulty and hotspots of current research.

In this study, the algorithm of measuring muscle thickness based on ultrasound image is discussed and analyzed. Gabor filtering algorithm and MVEF algorithm based on Hessian matrix are proposed. Through a series of denoising and smoothing of ultrasound muscle image, and then binary processing, the optimized effect is achieved.

\section{METHODS}

In this study, the research of muscle thickness recognition method is mainly carried out. The traditional method of measuring muscle thickness is mainly manual measurement, by selecting the reference point between the upper and lower layers of muscle membrane as the basis, and then using the scale on the screen to measure the muscle thickness. ${ }^{8}$

\section{Gabor filtering algorithm}

In this study, firstly, Gaussian filtering algorithm is applied to smooth the original image. After processing, the image will be divided into many image blocks, which do not overlap each other. If its size is $W \times W$, the pixels in the image are set. Assuming that the gradients of $x$ direction and $y$ direction are $\partial_{x}(i, j)$ and $\partial_{\mathrm{y}}(i, j)$ respectively, the initial local direction of each image block can be calculated by Kass principle. The equation is as follows:

$$
\operatorname{sum}_{x}(i, j)=\sum_{u=i-w / 2}^{i+w / 2} \sum_{v=j-w / 2}^{j+w / 2} 2 \partial_{x}(u, v) \partial_{y}(u, v)
$$

$$
\operatorname{sum}_{y}(i, j)=\sum_{u=i-w / 2}^{i+w / 2} \sum_{v=j-w / 2}^{j+w / 2}\left(\partial_{x}^{2}(u, v) \partial_{y}^{2}(u, v)\right)
$$

$$
\theta(i, j)=\frac{\pi}{2}+\frac{1}{2} \tan ^{-1}\left(\frac{\operatorname{sum}_{y}(i, j)}{\operatorname{sum}_{x}(i, j)}\right)
$$

In the above equation, the least square estimation of the image block direction with the center pixel of $(\mathrm{i}, \mathrm{j})$ is represented by $\theta(i, j)$. The equation for evaluating the reliability and consistency of azimuth field is as follows:

$$
R(i, j)=\frac{\left(\sum_{\Gamma}\left(\partial_{i}^{2}-\partial_{j}^{2}\right)\right)^{2}+4\left(\sum_{\Gamma} \partial_{i} \partial_{j}\right)^{2}}{\left(\sum_{\Gamma}\left(\partial_{i}^{2}+\partial_{j}^{2}\right)\right)^{2}}
$$

In the equation, the smallest adjacent area with pixels $(i, j)$ is represented by $\Gamma$. There is a direct relationship between its size and local frequency. The value range of $R(i, j)$ is 0 to 1 . Among them, the limit value 0 represents the isotropic region, and the limit value 1 represents the region with strong direction.

After calculating the image direction and frequency, the form of Gabor filtering is as follows:

$$
h(x, y)=\exp \left(-\frac{1}{2}\left[\frac{x^{2}}{\sigma_{x}^{2}}+\frac{y^{2}}{\sigma_{y}^{2}}\right]\right) \cos \left(2 \pi \mu_{0} x\right)
$$

$\mu_{0}$ in the equation represents the frequency of the sine curve. The window radius of signal in $x$ direction is represented by $\sigma_{x}$, and the window radius of signal in y direction is represented by $\sigma_{y}$. The corresponding Fourier transform equation is as follows:

$$
\begin{aligned}
& H(u, v)=A\left(\exp \left(-\frac{1}{2}\left[\frac{\left(u-u_{0}\right) 2}{\sigma_{u}^{2}}+\frac{v 2}{\sigma_{v}^{2}}\right]\right)\right. \\
& \left.+\exp \left(-\frac{1}{2}\left[\frac{\left(u+u_{0}\right) 2}{\sigma_{u}^{2}}+\frac{v^{2}}{\sigma_{v}^{2}}\right]\right)\right)
\end{aligned}
$$

$$
\sigma_{u}=\frac{1}{2} \pi \sigma_{x}
$$

$$
\sigma_{y}=\frac{1}{2} \pi \sigma_{y}
$$

$$
A=2 \pi \sigma_{x} \sigma_{y}
$$

In this study, $\sigma_{x}$ and $\sigma_{y}$ of all clinical images are equal to 4. 


\section{MVEF algorithm based on Hessian matrix}

Based on the longitudinal ultrasound muscle image, it can be seen that the gray area in the image represents the muscle nerve bundle, and the vascular structure of the upper and lower muscle membranes is a bright area. In this study, the image is mainly enhanced, and the applied algorithm is MVEF algorithm based on Hessian matrix. First, it is necessary to construct Hessian matrix. For the two-dimensional input image, the second-order partial derivative is used to construct the matrix whose pixels are $(i, y)$. The equation is as follows:

$$
H=\left[\begin{array}{ll}
f_{x x} & f_{x y} \\
f_{y x} & f_{y y}
\end{array}\right]
$$

Among them, $\mathrm{fxx}, \mathrm{fxy}, \mathrm{fyx}$, fyy in the equation represent the $\mathrm{x}$ direction, $x y$ direction and second-order partial differential in $y$ direction of two-dimensional image $f(x, y)$. The equation of the second order partial differential in $\mathrm{X}$ direction is as follows:

$$
f_{x x}=\frac{\partial^{2} f}{\partial x^{2}}=f(x-1, y)+f(x+1, y)-2 f(x, y)
$$

The second-order partial differential equation in $Y$ direction is as follows:

$$
f_{y y}=\frac{\partial^{2} f}{\partial y^{2}}=f(x, y-1)+f(x, y+1)-2 f(x, y)
$$

The mixed partial differential equation in $\mathrm{X}$ and $\mathrm{Y}$ directions is as follows:

$$
\begin{aligned}
& f_{x y}=f_{y x} \frac{\partial^{2} f}{\partial_{x} \partial_{y}}=f(x+1, y+1)+f(x, y) \\
& -f(x+1, y)-f(x, y+1)
\end{aligned}
$$

Then, two eigenvalues of the image are applied to further enhance the structure of the filter. The eigenvalues are represented by $\lambda_{1}$ and $\lambda_{2}$ respectively. The calculation equation is as follows:

$$
\lambda_{1}=k+\sqrt{k^{2}-Q^{2}}, \lambda_{2}=K-\sqrt{k^{2}-Q^{2}}
$$

$$
k=\left(f_{x x}+f_{y y}\right) / 2, Q=\sqrt{f_{x x} f_{y y}-f_{x y} f_{y x}}
$$

In the process of image processing, the eigenvalues of the constructed matrix are mainly used to determine the corner points on the image. In the image, if the density of a point changes dramatically, then the point is called a corner. At this time, the edge of the image can be detected by using the eigenvalue. The eigenvalue of the matrix represents the intensity of the image edge. The eigenvector of the matrix represents the direction of the image edge.

\section{Automatic estimation of muscle thickness based on Hough transform}

In this study, Hough transform is used to estimate the thickness of muscle automatically. First, it is necessary to mark the position of the upper and lower muscle membranes correctly, and then estimate the average thickness. The basic principle of Hough transform is to find the intersecting lines by applying the collinear points in image space through the duality between points and lines. In addition, by the same way, all lines intersecting the same point will correspond to the collinear points in the image space. Based on this principle, the following equation can be obtained:

$$
m=-x_{i} c+y_{i}
$$

The above equation represents a straight line generated by a fixed point in a cm plane. This fixed point is represented by (xi, yi). In addition, the second fixed point ( $\mathrm{xj}, \mathrm{yj})$ can also generate a straight line, which will intersect with the related straight line (xi, yi), and the intersecting point is recorded as $(c, m)$. In the equation, $c$ represents the slope of the line containing points ( $\mathrm{xi}, \mathrm{yi})$ and $(\mathrm{xj}, \mathrm{yj})$ on the xy plane. $\mathrm{m}$ represents the intercept of the line containing points ( $\mathrm{xi}, \mathrm{yi})$ and $(\mathrm{x}, \mathrm{yj})$ on the $\mathrm{XY}$ plane.

The following Figure 1 shows the dual relationship between points and lines. Figure A shows a point in the same line in the image space. Figure B shows the straight line in space after mapping the points on the straight line in the image. After the points on the line are transformed by Hough transform, all the lines in the corresponding space will intersect at the same point. As long as the position of the point is known, the position of the line and the specific parameters can be further confirmed.

Through the principle, all the lines in the space corresponding to the image points can be drawn, but the slope of the line is infinitely increased, or even close to the vertical direction. Therefore, in this study, a standard expression equation of straight line is established as follows:

$$
\rho=x \cos \theta+y \sin \theta
$$

In the equation, $\theta$ represents the angle between the line passing through the origin and the x-axis direction, and $\rho$ represents the vertical distance from the origin to the line, as shown in the following Figure 2

Before the automatic estimation of muscle thickness, the initial processing of muscle image is needed. The first step is to use the optimized adaptive bilateral filtering algorithm to process the image and denoise it. Then, Gabor filter or MVEF algorithm is used to enhance the image. After that, the image is binarized again. In the acquired image, the two fasciae are separated. After that, the characteristics of the acquired ultrasound muscle image are applied to find two peak points. The positions of the upper and lower fascia in the image are marked. Then, according to the previously marked information, the sum of the distances between the upper and lower lines at the corresponding points is calculated. The ratio of area to muscle length represents the average thickness of muscle. The width of the image represents the length of the muscle.

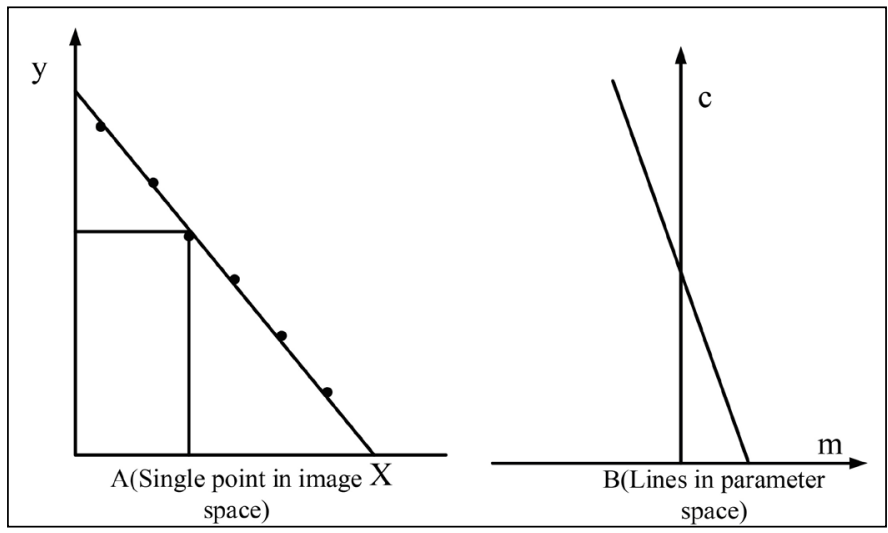

Figure 1. Dual diagram of point in image space and line in parameter space. 


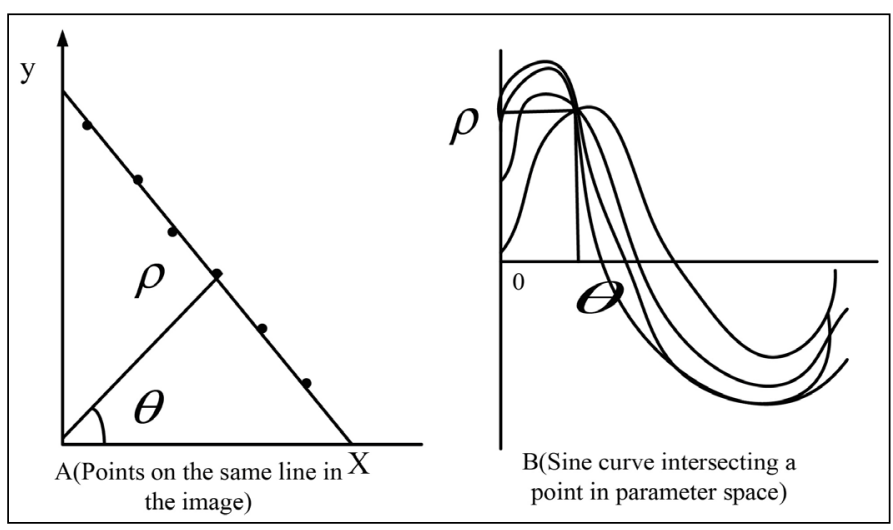

Figure 2. Point-line dual diagram under polar coordinate equation.

\section{Data acquisition}

In this study, three men are taken as subjects. Then, its human gastrocnemius muscle is used as the main muscle group for testing. The three subjects have no previous history of muscular neuropathy. Before the experiment, the subjects are informed of the procedure and steps. In addition, they sign the relevant consent form. Moreover, the experiment is approved by the ethics committee.

Before the experimental test, the subjects need to perform the dorsiflexion in the prone position. Among them, the main purpose of the real-time B-ultrasonic scanner (model: EUB-8500, Hitachi Medical Corporation, Japan) of the linear array probe (model: EUP-L53L, 5.010.0MHz, Hitachi Medical Corporation, Japan) is to collect ultrasonic images and analyze them. During the test, the ultrasonic probe should be placed on the gastrocnemius muscle abdomen and parallel to its longitudinal direction. Ultrasonic couplant is applied to achieve the purpose of close fitting. Then, the ultrasonic probe is placed in a container made of foam as raw material to avoid the sliding of the probe. The time of each subject's back bending movement is 5 seconds. Through the video acquisition card ( $\mathrm{PCl}-1411$, National Instruments Corporation, USA), the ultrasonic image can be further acquired. Finally, the image is operated offline. Then, Matlab and SPSS are used to analyze the data.

\section{RESULTS}

After processing, a certain frame of muscle image is obtained as shown in Figure 3 below. The 300 images obtained by experiments are enhanced by Gabor filter or MVEF algorithm. The results of Gabor filter and MVEF algorithm are $42.5 \mathrm{~mm}$ and $43.43 \mathrm{~mm}$ respectively. Then, the principle of Hough transform is applied to transform it. It can be found that both the superior and inferior sarcolemma can be detected as a straight line. (Figure 4)

The square of correlation coefficients are $91.3 \%, 91.3 \%$ and $87.8 \%$ respectively. The Bland Altman diagram is applied to compare and analyze the consistency of the three measurement methods, as shown in the Figure 5 below. The two horizontal lines in the figure represent the upper and lower limits of the $95 \%$ consistency limit, and the solid line in the middle represents the mean value of the result difference. The closer the solid line is to 0 , the smaller the difference is. As can be seen from the Figure 6 below, the difference between the manual measurement and the estimation results based on Gabor filtering algorithm is $1.45 \pm 0.48 \mathrm{~mm}$. The difference between the results of manual measurement and MVEF algorithm is $1.38 \pm 0.56 \mathrm{~mm}$. The computation time of the two algorithms is 5 seconds and 0.3 seconds respectively.

The algorithm proposed in this study was applied to patients with unilateral limb dysfunction. (Figures 7 and 8) It can be seen that when muscle fibers contract, the sensitivity of left healthy limbs is better than that of right healthy limbs. The results show that the proposed algorithm can directly and effectively measure the depth of muscle and can well reflect the contractility of skeletal muscle.

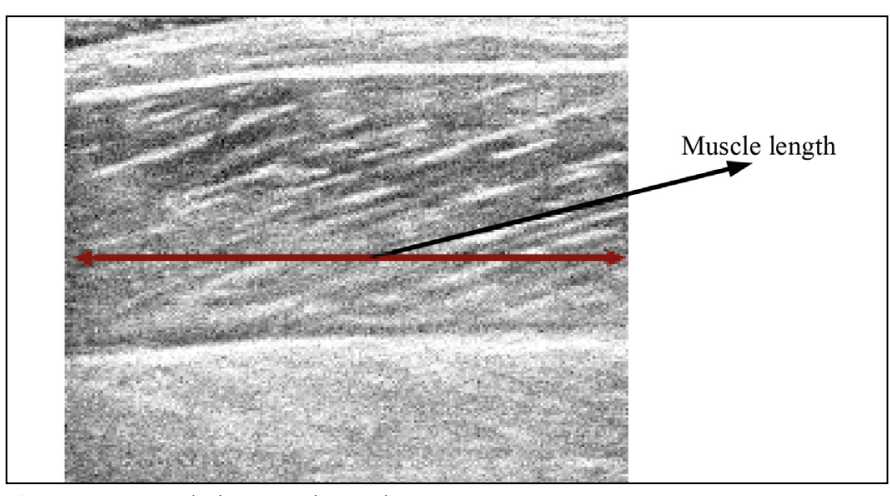

Figure 3. Original ultrasound muscle image.

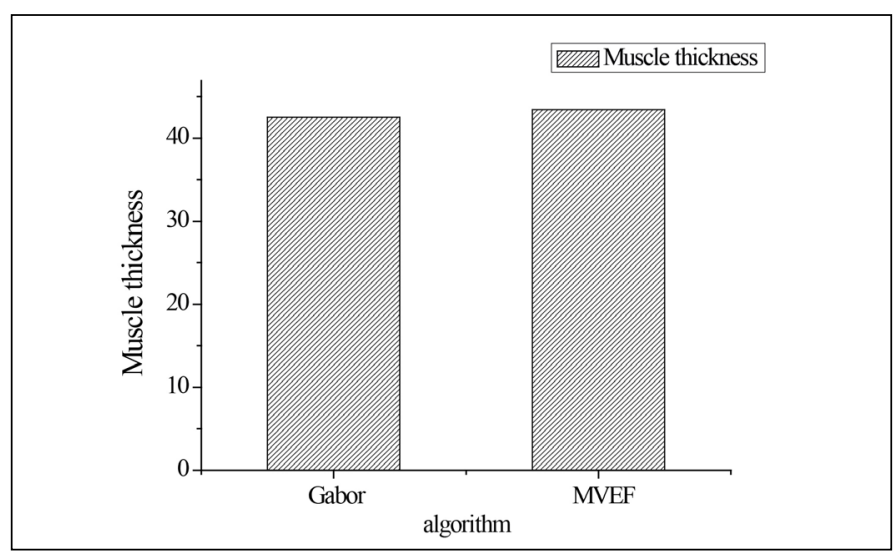

Figure 4. Enhancement results based on Gabor filter and MVEF algorithm.

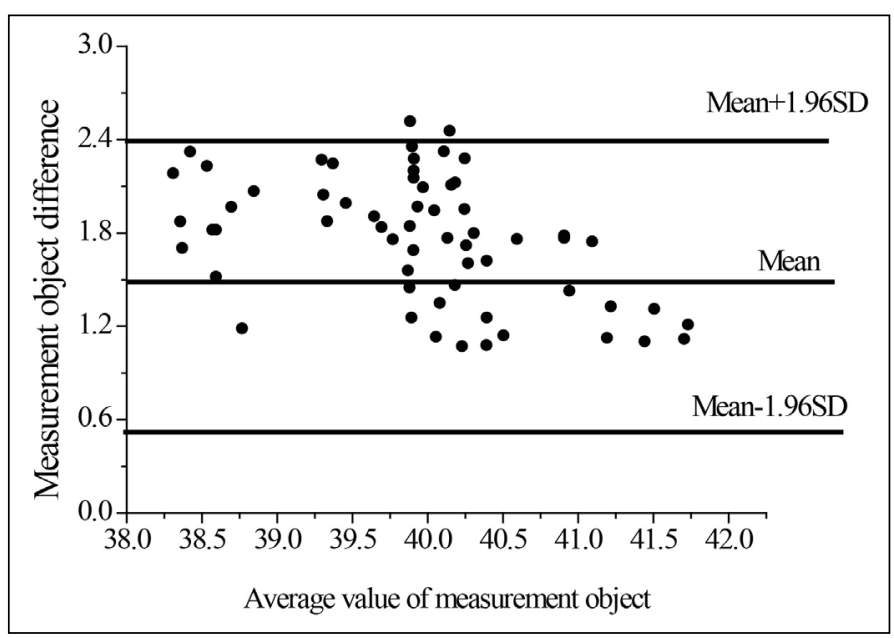

Figure 5. Bland-Altman graph based on Gabor filtering algorithm.

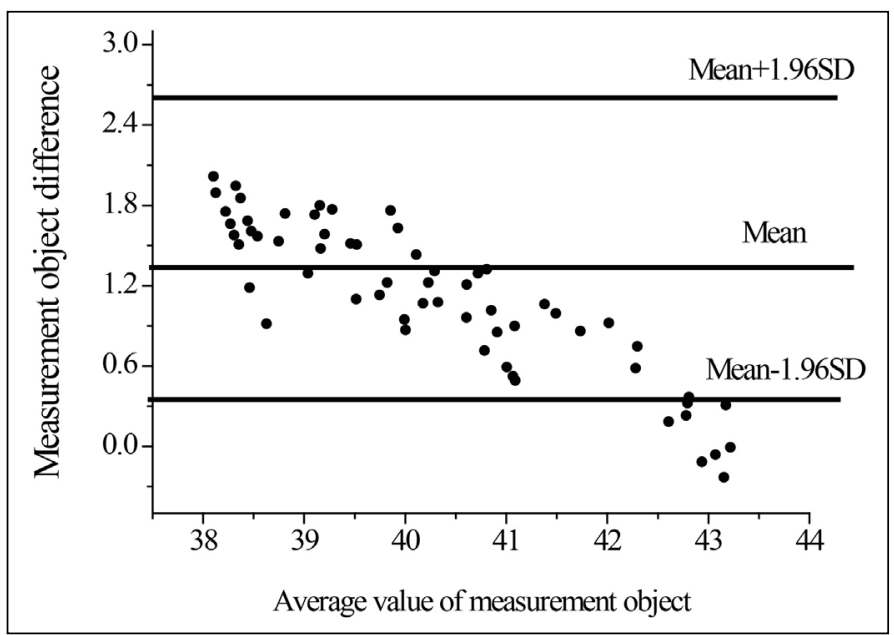

Figure 6. Bland-Altman graph based on MVEF algorithm. 


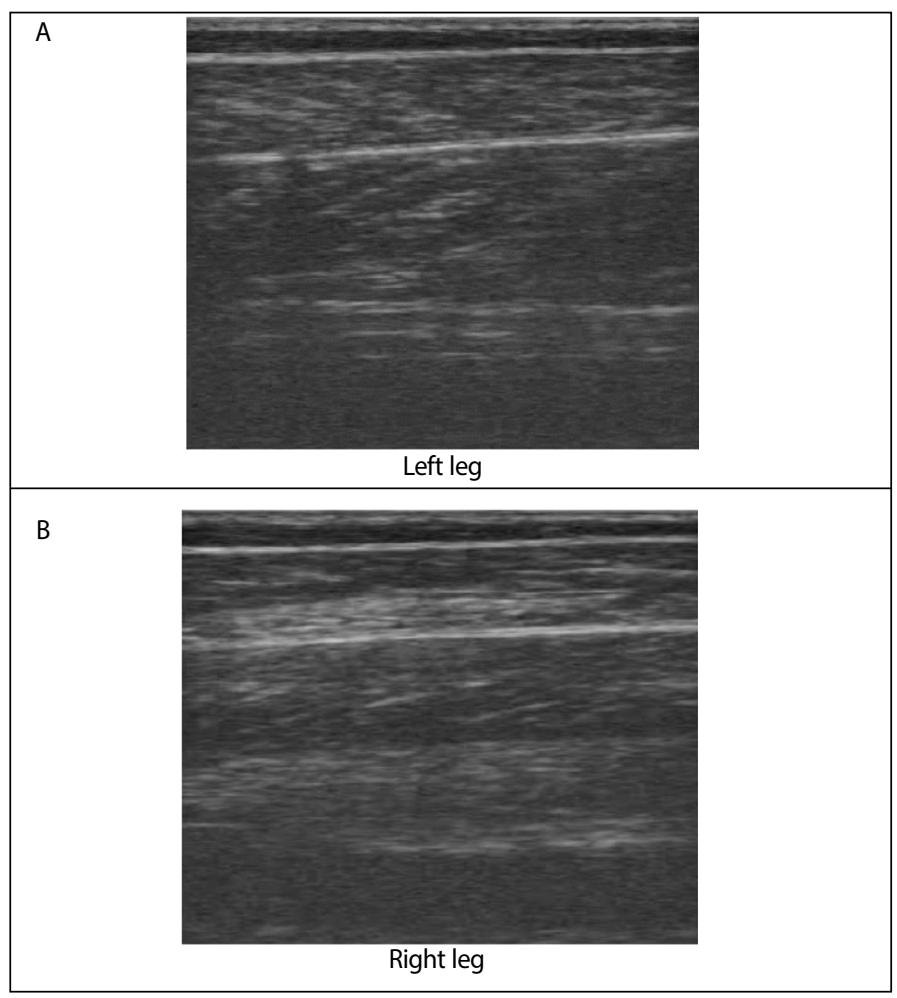

Figure 7. Ultrasonic image of the patient's leg.

\section{DISCUSSION}

In this study, two new algorithms, GABOR filter algorithms and MVEF algorithms were proposed. The algorithm can be used to quickly accurately measure the depth of muscle, avoiding the disadvantages of traditional manual measurement methods. The experimental results show that the number of related coefficients of manual measurement, Gabor filter and MVEF algorithm is $91.3 \%, 91.3 \%$ and $87.8 \%$, respectively. The difference between manual measurement and estimation results based on GABOR filter algorithm is $1.45 \pm 0.48 \mathrm{~mm}$, and the difference between manual measurement and MVEF algorithm is $1.38 \pm 0.56 \mathrm{~mm}$.

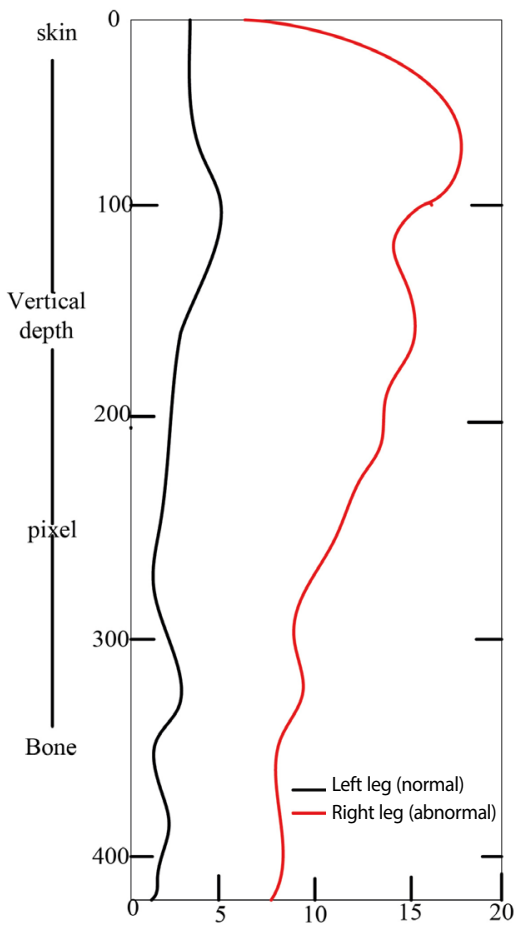

Figure 8. Quantitative assessment of muscle status in patients with dyskinesia in the experiment.

The calculation time of the MVEF algorithm and the Gabor algorithm is 5 seconds and 0.3 seconds, respectively.

\section{CONCLUSION}

The proposed algorithm has certain validity and practical application value. however, in this study, the muscle groups tested were relatively limited, so it is necessary to further expand the research direction and increase more muscle groups.

The author declare no potential conflict of interest related to this article

AUTHORS' CONTRIBUTIONS: Cheng Wang designed two new algorithms, GABOR filter algorithms and MVEF algorithms, which can be used to quickly accurately measure the depth of muscle, avoiding the disadvantages of traditional manual measurement methods.

\section{REFERENCES}

1. Bin Y, De Cheng W, Wei WZ, Hui L. Muscle gap approach under a minimally invasive channel technique for treating long segmental lumbar spinal stenosis: A retrospective study. Medicine (Baltimore). 2017;96(32):e7779.

2. Tabebordbar M, Zhu K, Cheng JKW, Chew WL, Widrick JJ, Yan WX, et al. In vivo gene editing in dystrophic mouse muscle and muscle stem cells. Science. 2016;351(6271):407-11.

3. W. Liu, Shuang Li, Kang Wang. Application of ultrasound biomicroscopy for measuring the thickness of levator palpebrae muscle in normal population. International Eye Science. 2016;16(2);370-2.

4. Zhou ZY, Li A, Wang LG, Irwin DL. DNA methylation signatures of long intergenic noncoding RNAs in porcine adipose and muscle tissues. Scientific Reports. 2015;5;15435

5. Hoglund LT, Pontiggia L, Kelly JD 4th. A 6-week hip muscle strengthening and lumbopelvic-hip core stabilization program to improve pain, function, and quality of life in persons with patellofemoral osteoarthritis: a feasibility pilot study. Pilot Feasibility Stud. 2018;4:70.

6. Ophoff J, Van Proeyen K, Callewaert F, De Gendt K, De Bock K, Verhoeven G, et al. Androgen signaling in myocytes contributes to the maintenance of muscle mass and fiber type regulation but not to muscle strength or fatigue. Endocrinology. 2016 [cited 202121 Jun];8;8. Available from: https://europepmc. org/article/med/19264874

7. Yin $\mathrm{N}$, Song T, Wu J, Chen B, Ma H, Zhao Z, et al. Unilateral microform cleft lip repair: application of muscle tension line group theory. J Craniofac Surg. 2015;26(2):343-6.

8. Espejo-Antúnez L, López-Miñarro PA, Garrido-Ardila EM, Castillo-Lozano R, Domínguez-Vera P, Maya-Martín J, et al. A comparison of acute effects between Kinesio tape and electrical muscle elongation in hamstring extensibility. J Back Musculoskelet Rehabil. 2015;28(1):93-100. 